\title{
FESTÍN DEL HORROR: LA COMIDA SINIESTRA EN «ALTA COCINA», DE AMPARO DÁVILA
}

\author{
LiLIANA COLANZI \\ Cornell University \\ lc566@cornell.edu
}

Recibido: 10-02-2021

Aceptado: 17-03-2021

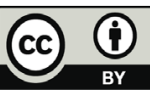

RESUMEN

Un aspecto de la obra de Amparo Dávila (México, 1928-2020) que no ha sido muy estudiado es el que tiene que ver con el horror gastronómico, la representación de la comida como fuente de abyección y de espanto. El primer libro de Amparo Dávila, Tiempo destrozado (1959), incluye dos cuentos en los que la comida y la cocina están codificadas en un registro gótico: «Alta cocina» y el relato homónimo «Tiempo destrozado». En estos cuentos la comida se vuelve extraña y repulsiva, atraviesa inquietantes metamorfosis y genera incertidumbre intelectual acerca de su naturaleza. En este ensayo me concentraré en «Alta cocina», que es el texto donde se desarrolla más la experiencia del horror alimenticio, para indagar la manera en que el cuento hace estallar la frontera entre lo humano y lo animal y pone en entredicho el binarismo civilización/barbarie. Asimismo, analizaré la forma en que un espacio históricamente asociado a la mujer como la cocina se presenta oscuro, siniestro y amenazante.

Palabras clave: Afood horror; Amparo Dávila; Latin American horror.

\section{ABSTRACT}

An aspect of the work of Amparo Dávila (Mexico 1928-2020) that has not been much studied is that which has to do with food horror, the representation of food as a source of abjection and terror. Amparo Dávila's first book Tiempo destrozado (1959) includes 
two short stories in which food and the kitchen are codified in a gothic register: «Alta cocina» and the homonymous story «Tiempo destrozado». In these stories, food becomes strange and repulsive, undergoes disturbing metamorphoses and generates intellectual uncertainty about its nature. In this work I will focus on «Alta cocina», which is the text where the experience of gastronomic horror is most developed, to investigate the way in which the short story complicates the boundary between the human and the animal and calls into question the civilization / barbarism binary concept. Also, I will analyze the way in which a space historically associated with women such as the kitchen appears as dark, sinister and threateninge.

KEY-WORDs: Amparo Dávila; poetic attitude; atmospheres; monstrosity; sinister.

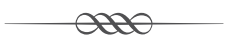

La obra de Amparo Dávila ha sido estudiada por su abordaje del horror conectado a los espacios domésticos y opresivos, a la experiencia de las mujeres en una sociedad patriarcal y a la amenaza de criaturas monstruosas en el límite entre lo animal y lo humano. Los críticos han señalado que los cuentos de Dávila crean atmósferas en las que predominan la angustia, la culpa y la sensación de lo ominoso, con frecuencia protagonizadas por personajes que presentan estados de conciencia alterados. Hay un aspecto de su obra, sin embargo, que no ha concitado demasiada atención, y es el que tiene que ver con el horror gastronómico, la representación de la comida como fuente de abyección y de espanto.

Los alimentos siempre han tenido un costado inquietante. Como ya lo señaló Mary Douglas en su influyente Purity and Danger, la aversión que provocan determinadas sustancias en diversas culturas está asociada a ideas de limpieza y pureza; la sensación de revulsión o disgusto no está necesariamente conectada con el miedo, sino con lo que una cultura considera prohibido o execrable, es decir, con la idea de un límite que es transgredido. Sustancias corporales como el sudor, la sangre, la saliva o las heces son vistas como abominables porque escapan los límites del cuerpo (Douglas, 1996: 122). Por su parte, el gótico y el horror han explorado las ansiedades subyacentes en la cultura con respecto a qué se come y de qué manera. Tanto las historias de vampiros como las de zombies abordan el terror primitivo del ser humano de convertirse en alimento de otros seres voraces, así como la transgresión de tabúes sobre la ingesta de sangre y sobre el canibalismo; estas figuras de lo 
monstruoso sirven para interrogarnos acerca de la industria alimenticia, las normas culturales y nuestra relación con la comida.

El primer libro de Amparo Dávila, Tiempo destrozado (1959), incluye dos cuentos en los que la comida y la cocina están codificadas en un registro gótico: «Alta cocina» y el relato homónimo «Tiempo destrozado». En estos cuentos la comida se vuelve extraña y repulsiva, atraviesa inquietantes metamorfosis y genera incertidumbre intelectual acerca de su naturaleza. Sin embargo, me concentraré en «Alta cocina», que es el texto donde se desarrolla más la experiencia del horror gastronómico. ¿Qué ansiedades permanecen latentes en aquello que denominamos comida? ¿Qué tabúes y límites son transgredidos? ¿Qué violencias están ocultan en expresiones civilizatorias como la gastronomía?

«Alta cocina» cuestiona nuestro vínculo con los animales, con quienes sostenemos una relación bastante paradójica: por un lado, son adorados como mascotas y, por otro, son brutalmente sacrificados y descuartizados para convertirlos en comida. Este cuento resulta perturbador porque hace estallar la frontera entre lo humano y lo no humano y pone en entredicho el binarismo civilización/barbarie. ¿Qué pasa cuando la comida revela al animal muerto? ¿Qué animales son aptos para transformarse en comida y qué tenemos en común con ellos?

«Alta cocina» es un cuento brevísimo — apenas una página y medianarrado desde una voz masculina — ¿un joven? ¿un adulto? ¿un viejo?- que recuerda los domingos en familia, en los que se acostumbraba compartir un guiso muy apreciado y sabroso. Como muchos de los cuentos de Amparo Dávila, el clima perturbador se instala desde la primera línea: «Cuando oigo la lluvia golpear en las ventanas vuelvo a escuchar sus gritos» (2018: 49). Los gritos a los que se refiere el narrador pertenecen a las criaturas utilizadas para preparar este plato especial que deleita a toda la familia y que se ofrece como gesto deferencial a los invitados de honor; para ello, se arroja a las criaturas al agua hirviente, provocando que estas lancen espeluznantes gritos de agonía que alteran al narrador, pero que dejan indiferentes a la cocinera y el resto de la familia. El efecto siniestro está logrado a través del contraste entre el ambiente familiar y el horror que acontece en su seno con la anuencia de todos. El cuento presenta uno de los temas recurrentes en la obra de Dávila: el espacio de lo doméstico devenido lugar amenazante, desconocido y hostil que termina por consumir a los protagonistas, conduciéndolos hacia la locura, el colapso nervioso, el crimen o el encuentro sobrenatural.

En «Alta cocina» el hogar es el sitio donde se experimenta lo ominoso. En su ensayo Lo siniestro (también traducido en castellano como Lo inquietante 
o Lo ominoso), Sigmund Freud señala que «lo ominoso es aquella variedad de lo terrorífico que se remonta a lo consabido de antiguo, a lo familiar desde hace largo tiempo» (1992: 220). Freud ofrece un interesantísimo análisis de la palabra «heimlich», que es de donde proviene el término «unheimlich», «siniestro». Uno de los significados de «heimlich» hace referencia a aquello que debía permanecer oculto y disimulado y que de pronto sale a la luz; la otra acepción de «heimlich» es «perteneciente a la casa, a la familia; o que se considera perteneciente a ellas» (Freud, 1992: 222) y que se traduce como «familiar» en castellano. Lo siniestro es la experiencia de aquello que alguna vez fue conocido y familiar pero que regresa desfamiliarizado y extraño a través de la represión: algunas de las encarnaciones de lo ominoso son aquellas que generan dudas sobre si se está frente a algo vivo o muerto, como las muñecas, las estatuas o los autómatas, pero también los lugares que parecen estar poblados por fuerzas oscuras como las casas embrujadas.

En varios cuentos de Amparo Dávila el ámbito doméstico se vuelve siniestro por la irrupción de presencias enigmáticas, monstruosas y hostiles que alteran el orden conocido, como en «La señorita Julia», «El huésped», «Moisés y Gaspar» o «Música concreta». Sin embargo, en «Alta cocina» son los propios rituales familiares los que provocan extrañeza y horror, así como el espacio de la cocina, que está descrita de tal manera que evoca sensaciones poco acogedoras o agradables: «Recuerdo la sombría cocina y la olla donde los cocinaban, preparada y curtida por un viejo cocinero francés; la cuchara de madera muy oscurecida por el uso y a la cocinera gorda, despiadada, implacable ante el dolor. Aquellos gritos desgarradores no la conmovían, seguía atizando el fogón, soplando las brasas como si nada pasara» (Dávila, 2018: 49). Adjetivos como «sombrío», «despiadada», «implacable», la alusión a «gritos desgarradores», crean un campo semántico que asocia el hogar con la violencia, la crueldad y el temor, a diferencia de las sensaciones de confort o protección con las que generalmente se lo relaciona.

En Consuming Gothic. Food and Horror in Film, Lorna Piatti-Farnell señala que existe una inescapable otredad en el proceso de comer, ya que tanto si la comida es familiar o exótica, al alimentarnos asimilamos en el cuerpo una entidad diferente de nosotros, damos cabida en nuestro organismo a una materia ajena (2017: 4). Por un lado, Piatti-Farnell advierte que la cocina es un lugar de ordenamiento civilizatorio y de comportamiento normativo: «Kitchens function as metaphorical renderings of our culinary organisation and are, broadly speaking, far removed from any notion of unnaturality, Otherness, and monstrosity» (2017: 182-183); la cocina remite a la sensación de se- 
guridad proveniente de la interiorización de normas culturales que regulan aquello que es apto para comer y aquello que resulta detestable y sucio. Sin embargo, la autora también reconoce el «potencial gótico» de la cocina pues en este lugar la comida pasa por notables metamorfosis - como el paso de lo crudo a lo cocido, o la transformación de los ingredientes sueltos en un platillo (2017: 182)—, recordándonos la otredad constitutiva de toda comida. Pero también la representación de la cocina vinculada al caos, la violencia, el desorden y el horror sugiere una ruptura con las normas culturales que definen lo que es correcto y apropiado (Piatti-Farnell, 2017: 183). Más allá de estas razones, la cocina igualmente puede producir la experiencia de lo ominoso porque aquello que es considerado comida y por tanto materia inerte y fragmentada, como un bife, una pechuga o unas costillas, pueden recordarnos de pronto al animal que ha sido sacrificado y al animal que nosotros mismos somos: el cine de horror está poblado de escenas en las que los alimentos de pronto cobran vida o parecen estar poseídos. ${ }^{1}$

«Tiempo destrozado», el otro cuento de Dávila donde está presente el horror hacia los alimentos, funciona a partir de un cúmulo de sensaciones atemorizantes y siniestras, un zambullirse en el inconsciente y en los miedos atávicos. En una de sus secciones, la narradora llega a una huerta en compañía de sus padres y se siente atraída de inmediato por unas manzanas rojas que yacen en el fondo de un estanque y sobre las cuales pasan nadando unos peces de colores. La niña está tan fascinada por estas manzanas que se lanza al estanque y al hacerlo el agua salta inmediatamente, arrastrando a sus padres. Acongojada, la niña sale a buscarlos y en ese momento nota que todo se ha oscurecido, que sus padres no están y que el estanque se ha convertido en un charco de sangre: las deliciosas y redondas manzanas se transforman en sustancia abyecta. Aterida y con miedo, la niña se siente culpable por la desaparición de sus padres: «los había perdido, los había perdido y yo tenía la culpa...» (Dávila, 2018: 66). El deseo de la niña por las manzanas rojas y apetitosas se ha transformado en culpa, terror y rechazo ante la sangre. Como en la historia bíblica y en los cuentos de hadas, la manzana representa el deseo, la transgresión y el castigo.

En otra escena, la niña reacciona con pavor cuando se mancha toda la ropa al tocar a un borrego que ha sido sacrificado. Para hacerle olvidar el mal

1 La literatura latinoamericana más reciente también está explorando algunos tabúes con respecto a la comida: las novelas Cadáver exquisito (2017), de la argentina Agustina Bazterrica, y En el cuerpo una voz (2017), del boliviano Maximiliano Barrientos, muestran sociedades que por diferentes razones recurren al canibalismo. 
rato sus padres la mandan a la feria con Quintila - ¿una sirvienta? ¿una niñera? ¿un familiar?-, y después de dar varias vueltas en el carrusel Quintila le compra algodón rosa y nieve de vainilla. En ese momento la comida se vuelve siniestra: «el algodón se me hizo una bola en la garganta y vomité otra vez, y otra, tenía la boca llena de pelos, de pelos tiesos de sangre, nieve con pelos, algodón con sangre...» (Dávila, 2018: 68). El horror llega a través de olores, sabores y texturas inquietantes, pues remiten al animal sacrificado. El inocente algodón de azúcar transmuta en los pelos ensangrentados del borrego muerto, el dulce y refrescante espesor de la nieve se convierte en la cálida y repugnante viscosidad de la sangre: «Yo no quiero ese caldo espeso, voy a vomitar, no me den ese horrible caldo, es la sangre del borrego, está tibia, espesa» (Dávila, 2018: 68). El texto nunca explica de qué manera o con qué propósito se ha matado al borrego, sino que se sostiene en las sensaciones de rechazo que provoca el contacto con la sangre y su consumo. Como con las manzanas, al metamorfosear en otra cosa el algodón y la nieve muestran la antítesis del deseo: la repulsión. El borrego muerto en la casa familiar va a perseguir a la niña hasta el parque de diversiones - escenario por excelencia del horror-, para desdoblarse en los caballitos mecánicos del carrusel. En este cuento el deseo es engañoso y en cada instancia termina transformado en aversión.

En «Alta cocina», el protagonista es el único en encontrar intolerable y violenta la preparación del platillo que es la gloria familiar. Su madre se sentía «llena de orgullo» cuando otros le alababan el plato, que era reservado para «las visitas distinguidas y las muy apreciadas» (Dávila, 2018: 49). La cocinera, por su parte, se mostraba inconmovible ante los terribles gritos de las criaturas mientras eran cocinadas vivas. Otras lecturas de «Alta cocina» han notado que los personajes femeninos del cuento son crueles e insensibles: Escarpeta Sánchez, por ejemplo, apunta que las mujeres que aparecen en este relato no responden a estereotipos de abnegación y piedad de la cultura mexicana y que el padre está ausente de la casa familiar (2018: 134). Se trata de un mundo femenino siniestro y poco maternal; si la cocina ha sido históricamente el espacio asignado a la mujer, en «Alta cocina» el lugar de lo femenino se presenta oscuro, asesino, inmisericorde.

Mientras que las mujeres de la casa se muestran implacables, el protagonista, en cambio, recuerda con absoluto espanto esos chillidos agónicos que se prolongaban por un tiempo interminable, al punto que él debía cubrirse la cabeza con una almohada para atenuarlos, pese a lo cual seguían martillando en su interior: «Cuando despertaba, a medianoche, volvía a escucharlos. Nun- 
ca supe si aún estaban vivos, o si sus gritos se habían quedado dentro de mí, en mi cabeza, en mis oídos, fuera y dentro, martillando, desgarrando todo mi ser» (Dávila, 2018: 49).

Parte de la extrañeza que genera el cuento tiene que ver con el hecho de que no llega a saberse jamás qué son las criaturas en cuestión. Esta borradura es similar a la que ocurre en otros cuentos de Dávila como «El huésped»o «Moisés y Gaspar», en los que la naturaleza de la presencia indeseable nunca es del todo develada: los textos no revelan si se trata de animales, monstruos o aun seres humanos, y esta ambivalencia acentúa el efecto inquietante. En «El huésped» y en «Moisés y Gaspar» los seres no identificados son los que acosan o agreden a los humanos; por el contrario, en «Alta cocina» los humanos actúan con brutalidad con aquellos seres a quienes ven como comida.

Como en «El huésped»y «Moisés y Gaspar», la distorsión de la realidad en «Alta cocina» es narrada desde la experiencia del protagonista, sin un punto de vista externo que corrobore el fenómeno, lo cual convierte al personaje en un narrador poco fiable. Repasemos, por ejemplo, las circunstancias en las que escucha los gritos de las misteriosas criaturas: «Cuando despertaba, a medianoche, volvía a escucharlos. Nunca supe si aún estaban vivos, o si sus gritos se habían quedado dentro de mí, en mi cabeza, en mis oídos, fuera y dentro, martillando, desgarrando todo mi ser» (Dávila, 2018: 49). Dado que el narrador escucha gritos incluso cuando los seres no están cerca, el texto nos hace dudar de si los ruidos realmente provienen de las criaturas o si el protagonista los está imaginando.

La voz narrativa cuenta que los pequeños seres crecían en las huertas, apegados a los tallos, y que tenían pequeños ojos negros que se desprendían al ser hervidos. Estos ojos después asediarán al narrador, quien los verá «brillantes, húmedos de llanto», pegados a los cristales de las ventanas en los días lluviosos (2018:49-50); si bien la descripción sugiere que podría tratarse de caracoles, el hecho de que lloren los antropomorfiza, llevándolos al terreno de lo fantástico. Como ya hemos visto, la falta de un contrapunto narrativo permite desconfiar de la versión del protagonista, y es en esa vacilación entre dos posibles explicaciones - de acuerdo a la teoría desarrollada por Todorovque se juega el efecto fantástico del cuento.

La preparación del guiso recuerda a la del escargot, el plato de la gastronomía francesa que consiste en caracoles hervidos y que es considerado una exquisitez. En «Alta cocina» las criaturas son purgadas antes de cocinarlas y sometidas a un baño de agua salada, hierbas y vinagre, un procedimiento parecido al utilizado en la preparación del escargot, en el que los caracoles atravie- 
san ayunos - en ocasiones hasta de una o dos semanas - para forzarlos a expulsar babas y excrementos que podrían resultar tóxicos o contaminantes. Los caracoles son lavados y cepillados antes de ser arrojados al caldero; en ocasiones también se los deja por horas en el refrigerador debido a la creencia en que esto los insensibiliza ante el agua hirviendo, aunque dicha práctica en realidad prolonga la agonía de estos moluscos gasterópodos. Al entrar en contacto con el agua hirviendo, los caracoles se retuercen y sueltan baba, una reacción aversiva a un estímulo negativo. Los moluscos poseen un sistema nervioso bastante simple, lo cual ha despertado discusiones científicas acerca de su capacidad para sentir el dolor como lo hacen los mamíferos. Sin embargo, los estudios científicos demuestran que los caracoles sí intentan evadir a toda costa estímulos nocivos como las altas temperaturas, y que la exposición a opiáceos disminuye este comportamiento (Achaval et al, 2005). Algunos países como Suiza y Nueva Zelanda han prohibido hervir vivas a las langostas por considerar que sienten dolor; aunque el cerebro del crustáceo es muy diferente al de los humanos y procesan los estímulos de otras formas, las langostas intentan huir desesperadamente cuando intentan quemarlas, darles choques eléctricos o cortarlas, lo cual sería el equivalente a nuestra sensación de dolor.

A diferencia de los silenciosos caracoles, las criaturas del cuento de Amparo Dávila manifiestan su agonía con gritos espantosos e interminables. Que estos seres puedan gritar los hace más incómodos e inquietantes: no hay manera de negar la existencia de su dolor. En El animal que luego estoy si(gui) endo, Jacques Derrida recoge el planteamiento de Jeremy Bentham con respecto a la cuestión animal. Para Bentham, la pregunta a formularse no es la que durante siglos se planteó la filosofía, desde Aristóteles hasta Lacan: si los animales pueden pensar, razonar, hablar o hacer. La pregunta, para Bentham, es si los animales son capaces de sufrir (Derrida, 2008: 43-44). Para Derrida, la capacidad de sufrir es un vínculo innegable que tenemos con los animales, el que rompe la jerarquía que sitúa al ser humano por encima del resto de los seres vivos: «Aquí se aloja, como la manera más radical de pensar la finitud que compartimos con los animales, la mortalidad que pertenece a la finitud misma de la vida» (2008: 44). El sufrimiento y la muerte del animal nos confronta con nuestro cuerpo y con la certeza de nuestra finitud, que es la característica que nos hermana con todos los animales.

Al protagonista de «Alta cocina» le resulta imposible escuchar los penetrantes chillidos sin sentirse interpelado, sin que resuene en él el sufrimiento de las criaturas. Lo que produce una impresión tenebrosa en el cuento es que nadie más sea capaz de experimentar la misma perturbación: el horrendo 
procedimiento resulta para los demás rutinario y carente de interés. La familia y la cultura que normalizan esos actos muestran su costado monstruoso, bárbaro, violento. La gastronomía es uno de los rasgos civilizatorios, y más aún la denominada «alta cocina», que representa lo más selecto y sofisticado de una cultura. El gótico se hace presente aquí en la manera en que desestabiliza la noción de civilización/ barbarie. El profundo desasosiego del narrador nace de la intuición de que el horror y la barbarie existen en el seno de su propia familia y de la cultura. Medina Haro ha analizado «Alta cocina» desde la conexión entre el banquete y los rituales funerarios, y a partir de allí ha visto una alusión a las culturas prehispánicas y a sus ritos, «con el aspecto de crueldad que estos ritos implicaban, con la presencia de una víctima y de un victimario, del castigo que produce laceraciones y dolor, del espectáculo indeseable del sacrificio de otros» (2009: 200). Esta lectura hace un importante hincapié en la conexión entre comida y muerte, pero pasa por alto la referencia al «viejo cocinero francés» que preparaba la olla donde se cocinaban las criaturas (Medina Haro, 2009: 49) y a la receta similar a la de los escargots de Borgoña; el horror y la barbarie no provienen de las culturas precolombinas sino de lo más refinado de la cultura europea, a la que intenta emular esta familia. La comida se torna espantosa porque recuerda estos terribles rituales de tortura y al animal de donde proviene, a pesar de los esfuerzos de la cultura para ocultar este vínculo. Pero, además, el horror en este cuento está ligado a un espacio considerado femenino, como la cocina, y a un animal que simboliza los poderes femeninos, como el caracol. En su análisis sobre «Alta cocina», Ana Rosa Domenella ha apuntado que en la cultura azteca el caracol «simbolizaba la concepción, la preñez, el parto», y que en la religión mexica el dios lunar, Tecciztécatl, era representado dentro de una concha de caracol (2009: 81); a su vez, Laura López Morales menciona que para los aztecas «el caracol evoca la vulva con su baba» (2009: 161). Esta serie de símbolos y asociaciones evocan un universo femenino sombrío y macabro, o por lo menos así es percibido por el narrador.

En The Sexual Politics of Meat, Carol J. Adams afirma que los animales se convierten en referentes ausentes al sacrificarlos para el consumo: «Without animals there would be no meat eating, yet they are absent from the act of eating meat because they have been transformed into food» (2014: 66). El lenguaje contribuye aún más a borrar a los animales al denominarlos bife, pechuga, costillas o chuletas; de esta manera, la comida se separa del animal muerto a través de su fragmentación. Los mataderos contribuyen a acentuar esta separación: están ubicados en lugares aislados a los que pocos tienen acceso, ya 
que ofrecen un tipo de conocimiento que la gente prefiere ignorar, pues de otro modo probablemente reconsiderarían sus hábitos (Adams, 2014: 76).

En «Alta cocina», la preparación del guiso requiere criaturas vivas que además lanzan chillidos penetrantes, por lo cual resulta imposible separar al animal de la comida. Esto genera una angustia tan profunda en el narrador que lo lleva a intentar sabotear la preparación del platillo: cuando lo envían a comprar a los seres que son el ingrediente principal, finge no haberlos encontrado. El referente animal se ha vuelto ineludible y ha hecho visible el vínculo entre lo viviente. Así, los gritos de las criaturas producen el efecto de lo ominoso porque se asemejan a los sonidos humanos: "Chillaban a veces como recién nacidos, como ratones aplastados, como murciélagos, como gatos estrangulados, como mujeres histéricas...» (Dávila, 2018: 50).

En Amparo Dávila la cocina es gótica porque emborrona y diluye los límites entre civilización y barbarie, entre lo animal y lo humano. Con la mención a los chillidos como de recién nacidos y de mujeres histéricas, "Alta cocina» proyecta la tortura de esos seres a la esfera de lo humano, y el extrañamiento cognitivo convoca el horror de estas prácticas normalizadas por la cultura, haciéndolo imposible de obviar. Que esto suceda en un ámbito asociado a lo femenino contribuye a exacerbar la sensación de inquietud y a desnaturalizar los roles asignados a las mujeres. Queda mucho por explorar sobre la conexión de la cocina con lo gótico en la literatura latinoamericana; en su brevedad, este cuento es emblemático de una forma ominosa, y por ello más novedosa y original, de entender un espacio culturalmente domesticado.

\section{BiBLIOGRAFÍA}

Achaval, M., M.A.P. Penha, A. Swarowsky, P. Rigon, L.L. Xavier, G.G. Viola, y D.M. ZANCAN (2005): «The terrestrial Gastropoda Megalobulimus abbreviatus as a useful model for nociceptive experiments: effects of morphine and naloxone on thermal avoidance behavior», Brazilian Journal of Medical and Biological Research, 38(1), pp. 73-80.

Adams, Carol J. (2014): The Sexual Politics of Meat. A Feminist-Vegetarian Critical Theory, Bloomsbury Academic, Nueva York.

DÁvila, Amparo (2018): Cuentos reunidos, Fondo de Cultura Económica, Ciudad de México.

Derrida, Jacques (2008): El animal que luego estoy si(gui)endo, trad. Cristina de Peretti y Cristina Rodríguez Marciel, Editorial Trotta, Madrid. 
Domenella, Ana Rosa (2009): «El banquete ominoso: "Alta cocina” de Amparo Dávila», en Regina Cardoso Nelky y Laura Cázares (eds.), Amparo Dávila. Bordar el abismo, Tecnológico de Monterrey, Ciudad de México, pp. 77-88.

Douglas, Mary (1996): Purity and Danger. An analysis of the concepts of pollution and taboo [1966], Routledge, Londres y Nueva York.

EsCARPETA SÁnCheZ, José Ángel (1998): «Cuatro visiones literarias acerca de la cocina: Dávila, Castellanos, Pacheco y Mastretta», Tema y variaciones de literatura. Escritoras mexicanas del siglo XX, núm. 12, p. 127-141.

FreUd, Sigmund (1992): Obras completas, Vol. 17 (1917-1919), trad. José L. Etcheverry, Amorrortu editores, Buenos Aires.

López Morales, Laura (2009): «Para exorcizar a la bestia», en Regina Cardoso Nelky y Laura Cázares (eds.), Amparo Dávila. Bordar el abismo, Tecnológico de Monterrey, Ciudad de México, pp. 77-88.

Medina Haro, Yolanda Luz María (2009): Tiempo destrozado de Amparo Dávila: una fractura del tiempo por donde se cuelan el mito y/o la fantasía, Universidad Iberoamericana, Ciudad de México.

Piatti-Farnell, Lorna (2017): Consuming Gothic. Food and Horror in Film, Palgrave MacMillan, Londres. (ebook)

Todorov, Tzvetan (1994): Introducción a la literatura fantástica, trad. Silvia Delpy, Ediciones Coyoacán, México. 